\title{
Unlocking value for a circular economy through 3D printing: A research agenda
}

\author{
M. Despeisse ${ }^{\text {a }}$, M. Baumers ${ }^{\text {b }}$, P. Brown ${ }^{\text {c }}$, F. Charnley ${ }^{\text {d }}$, S.J. Ford ${ }^{\text {a }}$, A. Garmulewicz ${ }^{\text {e }}$, \\ S. Knowles ${ }^{\text {f }}$, T.H.W. Minshall a, L. Mortara ${ }^{\text {a }}$, F.P. Reed-Tsochas ${ }^{g}$, J. Rowley ${ }^{\text {h }}$
}

anstitute for Manufacturing (IfM), University of Cambridge, Cambridge, UK

${ }^{\mathrm{b}}$ Additive Manufacturing and 3D Printing Research Group (3DPRG), University of Nottingham, Nottingham, UK

'Industrial Design Engineering, Delft University of Technology, The Netherlands

${ }^{\circledR}$ Cranfield Centre for Competitive Creative Design (C4D), Cranfield University, Cranfield, UK

'Facultad de Administración y Economía (FAE), Universidad de Santiago de Chile, Chile

${ }^{\mathrm{F}}$ Fila-Cycle, Sheffield, UK

:Saïd Business School (SBS), University of Oxford, Oxford, UK

${ }^{\mathrm{h}}$ Digits2Widgets (D2W), London, UK

Corresponding author:

E-mail address: md621@cam.ac.uk (M. Despeisse)

\begin{abstract}
The circular economy (CE) aims to radically improve resource efficiency by eliminating the concept of waste and leading to a shift away from the linear take-make-waste model. In a CE, resources are flowing in a circular manner either in a biocycle (biomass) or technocycle (inorganic materials). While early studies indicate that 3D printing (3DP) holds substantial promise for sustainability and the creation of a CE, there is no guarantee that it will do so. There is great uncertainty regarding whether the current trajectory of 3DP adoption is creating more circular material flows or if it is leading to an alternative scenario in which less eco-efficient localised production, demands for customised goods, and a higher rate of product obsolescence combine to bring about increased resource consumption. It is critical that $\mathrm{CE}$ principles are embedded into the new manufacturing system before the adoption of 3DP reaches a critical inflection point in which negative practices become entrenched. This paper, authored by both academic and industry experts, proposes a research agenda to determine enablers and barriers for 3DP to achieve a CE. We explore the two following overarching questions to discover what specific issues they entail: (1) How can a more distributed manufacturing system based on 3DP create a circular economy of closed-loop material flows? (2) What are the barriers to a circular 3D printing economy? We specifically examine six areas - design, supply chains, information flows, entrepreneurship, business models and education - with the aim of formulating a research agenda to enable 3DP to reach its full potential for a CE.
\end{abstract}




\section{Introduction}

\subsection{Background}

The emergence of new advanced manufacturing technologies creates opportunities for changing how manufacturing activities are organised. Alongside important advances in innovation processes, technologies may affect the distribution of manufacturing and the subsequent flow of materials and goods with many potential sustainability benefits (Gebler et al., 2014). Such benefits include the potential to move towards a Circular Economy (CE), which aims to radically improve the resource efficiency of society by eliminating the concept of waste and leading to a shift away from the linear takemake-waste model.

It is still unclear however what the implications of the value chain reconfigurations caused by those new technologies are, whether they can realistically enable a more circular use of resources, and under which circumstances they are truly beneficial from a sustainability viewpoint. This requires a better understanding of the information flows and the relationships between stakeholders along the product and material life cycles (Evans et al., 2009).

One such advanced technology is 3D printing (3DP, also known in industry as additive manufacturing). The standard definition of 3DP technology is "a process of joining materials to make objects from $3 \mathrm{D}$ model data, usually layer upon layer, as opposed to subtractive manufacturing methodologies" (ASTM, 2012). In other words, 3DP allows objects to be fabricated layer by layer in a continuous or incremental manner, enabling three dimensional objects to be 'printed' on demand (Petrovic et al., 2011).

Some of the most widely adopted 3DP technologies are material extrusion, vat photopolymerisation and powder bed fusion. Other technologies available include material jetting, binder jetting, directed energy deposition and sheet lamination. These technologies are able to process a variety of polymers, metals, ceramics and composites (Guo and Leu, 2013).

It is widely recognised that 3DP offers significant advantages in terms of design freedoms, mass customisation, co-creation and innovative business models (Berman, 2012; Petrick and Simpson, 2013; Ford and Despeisse, 2016; Rayna and Striukova, 2016).

Current industrial applications of 3DP are already enabling more circular production systems with the use of recycled and reclaimed materials as input for AM processes. For instance, in metal additive manufacturing,

\footnotetext{
${ }^{1}$ Information available from

http://www.3dsystems.com/shop/support/ekocycle/faq.
}

more than $95 \%$ of the unused powder can be locally filtered and reused directly (Vayre et al., 2012; Faludi et al., 2015a), while the other $5 \%$ can be sent to a centralised recycling facility to produce virgin powder. So not only is the process using less material due to its additive nature (i.e. material is added only were needed as opposed to subtractive processes which generate large amounts of material waste) but the system around the process is designed to enable a closed-loop circulation of materials.

Similarly, plastics used in 3DP are commonly recycled plastics, such as ABS, PLA and PET, and the filament itself often has a recycled content, e.g. EKOCYCLE Cube uses $25 \%$ recycled polyethylene terephthalate (rPET) in its cartridges ${ }^{1}$ and Recyclebot (waste plastic extruder) produces filament from $100 \%$ household polymer waste (Baechler et al., 2013). While, plastics are still recycled at low rates in centralised recycling facilities, distributed plastics recycling to produce filament for 3DP could help increased this rate at a lower economic and environmental cost (Kreiger et al., 2014).

These examples are showing that 3DP can facilitate the implementation of circularity concepts by directly using reclaimed and recycled materials, but also with more sustainable materials - "ones which are renewable or abundant, non-toxic, recyclable or compostable, and which have little embodied energy or resources" (Faludi et al., 2015b). In addition, due to the digital nature of the fabrication process, the designs can be modified and shared easily. As its technical performance improves, the potential to use 3DP as a direct manufacturing process is gradually being realised in sectors such as aerospace, automotive, construction, pharmaceuticals and healthcare where personalisation is key, e.g. hearing aids, orthodontics, prosthetics, and implants. These are at various stages of maturity and adoption, and new applications continue to be found as the technology further develops.

\subsection{Research aim and objectives}

Among the variety of advanced manufacturing technologies that are currently emerging, 3DP stands out as one with significant potential for changing the distribution of manufacturing and society as a whole (Huang et al., 2013; Lipson, 2012). To date, investigations by researchers into the sustainability implications of 3DP have looked at the potential impact at a broad level (Gebler et al., 2014; Kohtala, 2015; Ford and Despeisse, 2016) and have focussed on the issue of material and energy consumption (Baumers et al., 2011; Faludi et al., 2015a). This paper brings together academic and industry experts in the field to construct a research agenda for exploring the means through which 3DP can enable more sustainable modes of 
production and consumption, and unlock value in the $\mathrm{CE}$, doing so through investigating the following overarching questions:

- How can a more distributed manufacturing system based on 3D printing create a circular economy of closed-loop material flows?

- What are the barriers to a circular 3D printing economy?

Starting from the cross-disciplinary palette of questions identified by Ford et al. (2016), this paper derives research questions specific to the CE. Given the geographic location of the authors, these questions are approached from a UK perspective but are considered to be more widely generalisable.

\section{Research programme}

The issues covered within this paper are diverse and span the entire product and material life cycles (Fig. 1). The sections below explore six areas of research identified as critical to understand how 3DP can enable the move towards a CE, namely: (1) product, service and system design, (2) material supply chains, (3) information structure and flows, (4) entrepreneurial responses, (5) business model transformations, and (6) education and skills development. Accordingly, exploring these research areas requires a multidisciplinary approach and a systems-level perspective.

\subsection{Product, service and system design}

Designing for a CE requires a monumental shift in the way that organisations, designers and entrepreneurs develop, exploit and obtain value from products (Charnley et al., 2011; Bakker et al., 2014). There is an urgent need not only to address production processes, products and the provision of services, but to also redesign the patterns of consumption or lifestyles, as well as the institutions that underpin them (Vezzoli et al., 2015). However, the redesign task is not a simple one as there are strong interdependences between design, process and material selection. Manufacturing processes are not interchangeable as they usually require design adaptation and validation. The redesign also needs to account for the operational characteristics of the new manufacturing process, such as effective build volume utilisation and handling, variations in finish quality and material properties. This can be partly addressed through education (discussed in Section 2.6) and design software supporting optimisation for 3DP.

Design is particularly influential in how the entire value chain is configured in both forward and reverse processes (Schenkel et al., 2015). However, designers cannot wait for the development of a remanufacturing, reuse and/or recycling infrastructure and other alternative business models before they start to design for the CE; they must anticipate and prepare for the alternative economy, particularly where there is a long product lead time from initial concept to shop floor (Andrews, 2015).

3DP is proposed as a tool to enable design for a CE, but without a comprehensive understanding of the characteristics of the technology and resulting products that can align with CE principles, its use could be ill fated. Most existing approaches to design for a $\mathrm{CE}$ involve recovery at product and/or component level, where the implementation of maintenance, refurbishment and remanufacturing into industrial processes has been proposed as a means to extend the life of valuable components such as electrical and electronic goods and motor vehicles (Parker, 2010; Ellen MacArthur Foundation, 2013; Stahel, 2013). Consequently, design guidelines, principles and tools to support remanufacturing and refurbishment have been a fruitful topic for research, where many researchers have tried to improve ease of disassembly, material and component separation and reassembly for circular products (Sherwood and Shu, 2000; Sundin et al., 2012; Go et al., 2015).

Several sources also highlight the importance of accurate material selection during design, either purposeful to generate an additional benefit during or at end of life (Braungart and McDonough, 2002) or preventive, to reduce the environmental impact related to product creation (Allwood et al., 2011). However only the latter has been truly explored from a design perspective (Whalen and Peck, 2014; Peck et al., 2015).

In summary, the literature describing design guidelines suitable for a circular economy suggests necessary changes to incorporate the application of materials suitable for endof-life and the technical characteristics of modularity, disassembly and repair-friendly features into products. This would appear to still be a limited approach as the value of a product through its life cycle does not depend on its functionality and material integrity alone: its intangible value for the user is just as important (Tukker, 2015; Schenkel et al., 2015). However, these intangible aspects of a product, comprising mainly desirability factors, have been only exploited in the traditional linear model of "design for sales' (Bakker et al., 2014).

As many of the aforementioned product characteristics can be achieved by the use of 3DP, we propose to further investigate how 3DP aligns with the CE principles:

RQ1-1: What are the characteristics of 3DP processes and resulting products that enable $\mathrm{CE}$ principles such as re-use, modularity, upgrade, refurbishment and remanufacture? 


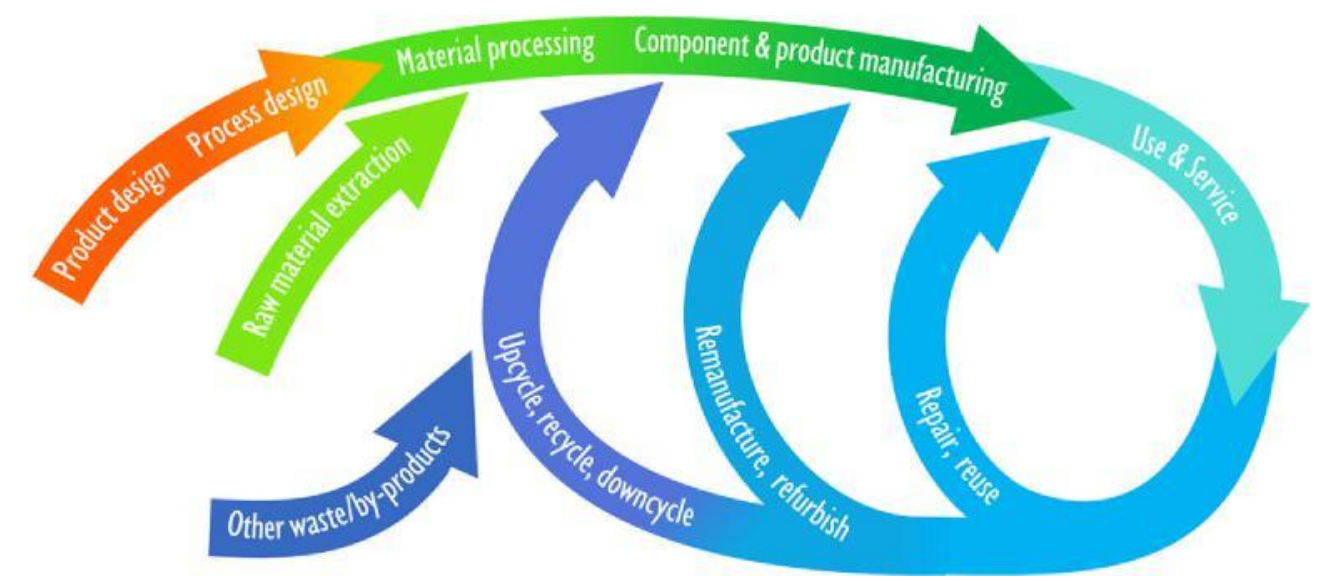

Fig. 1. The product and material life cycle perspective adopted in this paper. (adapted from Despeisse and Ford, 2015)

Life cycle assessments tools and existing guidelines for design for extended or multiple life cycles provide an important aid for decision making (Bakker et al., 2014) but must be complemented with the unique human cognitive capabilities (Khalili et al., 2015) needed to utilise them and assess performance in intangible terms; in design research this has been referred to as 'systems thinking' (Wright and Meadows, 2008; Joore and Brezet, 2015; Andrews, 2015) or 'life cycle thinking' (Vezzoli and Sciama, 2006; Hatcher et al., 2011; Bakker et al., 2014). In order to support circular economies, Alix and Vallespir (2010) highlight the need for new capabilities development, specifically when using new technologies and tools such as 3DP. Addressing the topic of education for circular economy is deemed significant, as authors frequently highlight the importance of labour in circular economies: it is the only intelligent renewable resource (Stahel, 2013; Khalili et al., 2015) capable of the versatility and adaptability needed to produce innovative solutions, much needed in a material effective world (Sempels and Hoffmann, 2013). This is assumed to be especially true for more creative trades, such as design and engineering (Andrews, 2015; Vezzoli et al., 2015).

Designers need to learn to design for longevity - through product repair, upgrades and remanufacturing, and a high perceived value - and to design for reduced environmental impact and increased efficiency through dematerialisation, design for disassembly, closed materials loops and service design (Andrews, 2015). Higher Education Institutions have key roles to play in fostering new generation of practitioners and design educators with the capabilities to design for a CE utilising advanced manufacturing tools and techniques. This will be further discussed in Section 2.6.

Furthermore, there is little evidence of the extent to which the existing tools and methods for the design of products for multiple life cycles and design of circular solutions are being used by designers in industry (Hatcher et al., 2011; Vezzoli et al., 2015). Several authors (King et al., 2006; Charter and Gray, 2008; Sundin et al., 2009; Go et al., 2015) have suggested that designers are not qualified to understand technical processes and reverse logistics (as described further in Section 2.6), and thus hinder the adoption of methods and tools developed to support design for circular product life cycles. Martinez et al. (2010) and Vezzoli et al. (2015) also identified conflicts between business functions and barriers in interdisciplinary communication as significant challenges for industrial implementation of product-service models. Future research needs to explore how to enable designers to consider $\mathrm{CE}$ principles when using 3DP and how this can be built into the design process in education and practice:

RQ1-2: How can we enable designers to consider CE principles when using 3DP and how can this be built into the design process?

\subsection{Material supply chains}

\subsubsection{Redistribution of material supplies: economies of scale and scope}

An important question is how 3DP, by introducing a change in the relationship between capital requirements and the minimum efficient scale of production, may influence the structure of material supply chains.

This question is based on the insight that 3DP taps into economies of scope rather than scale (although economies of scale still applies to some extent), reducing the need to hold large inventory (Brody and Pureswaran, 2013). Many applications of 3DP exhibit an absence of scale economies 
resulting from the indivisibility of manufacturing tooling; throughput-related economies of scale may apply however (Baumers et al., 2015). Corresponding lower barriers to market entry may allow for more distributed, flexible forms of production (Cotteleer, 2014). While this relationship may be understood in context of 3D printed goods, there remains the question of whether economies of scale and the distribution of material supply chains may change as a result.

For the CE, the structure of material supply chains has significant implications. For example, local, more flexible materials markets may be better suited to recycle highly distributed sources of consumer waste, avoiding information loss stemming from the aggregation of waste by large-scale recycling facilities. Furthermore, a more distributed materials market may incentivise the use of smaller concentrations of natural resources, leading to a reduction in transportation emissions and the environmental impact of intensive resource exploitation.

However, at present the market in raw materials for 3DP remains highly concentrated. Even though 3DP plastic is processed into filament by a range of both small and large companies, feedstock is supplied by a handful of large polymer producers. This follows from the present reality that polymer production from petrochemical and bio-based feedstock is capital intensive, leading to high barriers to entry (Witter, 2015). In these types of markets, the minimum efficient scale for production remains large (Chandler, 1990). This raises the question of the technical feasibility of smaller-scale distributed materials production. This is especially the case for recycled materials as they require large centralised processes to convert mixed plastic waste into single polymers suitable for reuse.

To understand whether the present concentration in the market may persist as 3DP develops, or whether a more distributed model of materials production may emerge, research is needed to investigate sources of rigidity in the concentration of raw materials markets for 3DP. Important questions involve the economic and technical challenges for materials supply, including economies of scale in production, and pre-processing and post-processing technologies. We suggest that quantifying the impact of $3 \mathrm{DP}$ on the raw material supply chains is necessary, and can complement qualitative field interviews from firms throughout the material value chain. Thus we derive the following research question to explore the impact of supply chain reconfigurations enabled or triggered by the adoption 3DP:

RQ2-1: What are the economic, organisational and sustainability impacts of 3DP on materials supply chains?

\footnotetext{
${ }^{2}$ See Filabot (www.filabot.com), Filastruder

(www.filastruder.com), Filafab

(http://d3dinnovations.com/filafab), RecycleBots
}

\subsubsection{Role of recycling systems in local materials supplies}

In recent scholarship and practice, there has been an increase in attention given to technologies that can recycle waste plastics for desktop 3DP, and the benefits associated. ${ }^{2}$ For example, a study by Kreiger et al. (2014) found that a distributed 3DP market supplied by distributed sources of recycled materials resulted in savings in embodied energy and carbon emissions compared to being supplied by a centralised recycling market when using readily identifiable single polymer types (e.g. milk jugs).

Relating this work to the model of a CE, if waste infrastructure is redesigned to serve a distributed production base, incentives may improve for increasing the circulation of material flows in the economy. This proposition can be explored by studying how the current infrastructure in metals and plastics recycling may have the capacity to supply a growing demand in a distributed 3DP market. By looking at the quantities of high quality waste that are currently undervalued in our recycling system due to their small concentration, estimates can be made as to the potential latent material value that $3 \mathrm{DP}$ could tap into when there is more distributed demand.

This prospect varies with the type of material being considered. For example, a study by Garmulewicz et al. (2016) found that a core challenge to using recycled plastics for 3DP at a local level was the quality of the feedstock and the level of technological sophistication. Considering waste metals, there are important technological questions to be asked concerning printability, quality control, and pre-and post-processing steps. A systematic inquiry into the sources of material value in current recycling infrastructure by material type is needed. To investigate this issue, we formulate the following research question:

RQ2-2: How can small-scale production, pre-processing and post-processing technologies for 3DP feedstock enable the localisation of material supply chains?

\subsubsection{Transparency in materials supply chains}

Transparency, including disclosure of material sources, production process, and ingredients, is an important consideration in the study of the relationship between 3DP material supply chains and the circular economy. Tracking and tracing data on materials can play an important part in enabling circular material flows (Ellen MacArthur Foundation, 2016). A lack of transparency in material supply chains may contribute to both concentrated market structure and a deficit in information needed to cycle waste materials into 3DP feedstock. Trade secrecy and patenting in materials

(http://www.appropedia.org/Recyclebot), MiniRecycleBot (http://reprap.org/wiki/MiniRecyclebot) and Mulier filament extruder (https://www.thingiverse.com/thing:380987). 
production, and the disclosure of material sources within 3DP supply chains are important for a $\mathrm{CE}$ research agenda.

As a more distributed market for 3DP continues to develop, demand for data on material characteristics and sources may change. We propose research into new market segments that may demand information on 3DP materials, and whether such market dynamics may relate to the potential for creating circular material flows with the following research question:

RQ2-3: As a more distributed market emerges for raw materials, including consumers and SMEs, is there an accompanying increase in demand for disclosure of material data?

\subsection{Information structure and flows}

\subsubsection{Information heuristics for a circular 3DP economy}

Through the absence of dedicated manufacturing tooling and changeover expenses, 3DP technology promises to be an extremely efficient approach to the manufacture of customised and differentiated products (Weller et al., 2015). The underlying economies of scope arise if there is a cost advantage in manufacturing multiple product variants on the level of the organisational unit (Panzar and Willig, 1981).

Based on the design freedoms engendered by 3DP processes (Hague et al., 2003), the technology has shown significant potential in a range of high value manufacturing applications, such as medical products, automotive and aerospace components, industrial machinery and high-end consumer products (Gibson et al., 2014). In the context of $\mathrm{CE}$, such products are known as "medium-lived complex products" and form a central focus point (Ellen MacArthur Foundation, 2013). By harnessing 3DP's dual advantages of being able to deposit complex and functional structures as well efficiently manufacturing individually differentiated units in small numbers (Tuck et al., 2008), the value proposition of such products can be improved and their useful lives can be extended.

However, the viability of extended-life assets hinges on their fitness for purpose and the degree of differentiation in terms of the target application. Only with such differentiation will the products' use-phase extension be preferable over substitution with new products. For a fully software mediated (Lanier, 2014) and toolless manufacturing process such as 3DP (Hague et al., 2003), unlocking manufacturing value requires two prerequisites regarding (1) design and (2) supply chain and production. Together they form the basis for a joined-up manufacturing information heuristic spanning end-users and manufacturers alike.

Firstly, application-specific data must be fed into manufacturing design and design validation processes preceding 3DP operations (Mellor et al., 2014). Only the incorporation of such data will yield the benefits obtainable from products differentiated to particular applications, for example resulting from optimisation-based design methodologies (Aremu et al., 2013). Moreover, advanced predictive design methodologies can be employed to anticipate future use-cases, which will extend the usefulness horizon even further. It is probable that the complementarity between 3DP and the supporting data structure will spawn products influenced by the information heuristic itself, thereby giving the rise to the concept of "Things-ofthe-Internet".

Secondly, the CE's focus on local manufacturing and the minimisation of environmental supply chain footprint will require efficient 3DP supply chains allowing for distributed manufacturing configurations minimising downstream logistics (Cotteleer and Joyce, 2014). This implies that networked production planning, scheduling and manufacturing execution functionality must be established to underpin 3DP.

We suggest that the information heuristics supporting the adoption of 3DP in the CE setting will result in the incorporation of a number of non-traditional activities on the operational level, including design and validation in the light of application-related data, process planning, and manufacturing execution and documentation. To further explore this issue, we derive the following research question:

RQ3-1: What types of information heuristics are needed to control a circular 3DP economy?

\subsubsection{Enabling sustainable consumption}

The long and complex supply chains found in mass manufacturing, which routinely span continents, complicate the analysis of resource flows. In this context, it has been noted that "if you can't measure, you can't manage" (Foran et al., 2005). Unlike conventional manufacturing technology, 3DP is a process capable of depositing complex product geometry in a single manufacturing process step. This means that, at least in principle, processing and assembly activities can be limited and very short supply chains are enabled, with an added side-effect of simplifying the measurement of resource consumption without having to consider long and complex supply chains (Baumers et al., 2013). Thus, the information heuristic proposed in the previous section contributes to inventory analysis, drawing together material and energy flows occurring throughout the product life cycle (Jiménez-González et al., 2000).

Despite the importance of societal and environmental impacts of engineering decisions (Maxwell and Van der Vorst, 2003), the consideration of private benefits and costs, which arise to organisations and individuals, are traditionally viewed as the determinants of technology adoption decisions (Stoneman, 2001). With the proposed information heuristic 
underpinning the adoption of 3DP in CE settings, essential data can be fed into "design for environment" methodologies (Telenko et al., 2008). Additionally, information can be provided to end-users and consumers directly to enable environmentally responsible decision making. In order to explore the role of information heuristics in changing consumption patterns in a $\mathrm{CE}$, we pose the following research question:

RQ3-2: How do information heuristics enable and incentivise more efficient patterns of consumption?

\subsubsection{Aligning private incentives and societal benefits}

For conventional manufacturing processes, it has been observed that minimum cost configurations do not necessarily minimise manufacturing energy consumption (Rajemi et al., 2010); thereby cost minimisation in commercial manufacturing can result in negative externalities.

By linking the environmental footprint of 3DP with the volume of material deposited, research on the energy efficiency of 3DP processes suggests that cost minimisation by the technology operator can be expected to coincide with the minimisation of process energy and material consumption (Baumers et al., 2011). The described relationship between operational variables results in correctly aligned incentives, where the private incentive of cost minimisation coincides with the deposition of the smallest amount of material. As discussed by Lovins (1996) in the context of energy inputs, the alignment of cost efficiency with the minimisation of the environmental impact of the process forms an important enabler for the minimisation of resource consumption.

\subsection{Entrepreneurial responses}

\subsubsection{New opportunities for 3DP application to create a CE}

The emergence of new technologies and industries creates new opportunities for entrepreneurial and innovative organisations. In some cases the innovators are established companies that leverage their existing capabilities and competences to enter and establish new markets (Tushman and Anderson, 1986). Such companies need to balance the exploitation of existing technologies with the exploration of new ones (March, 1991; Tushman and O'Reilly, 1996); a combination of factors including their aversion to risk, inflexibility and cultural inertia limit their ability to generate radical or disruptive innovations (Assink, 2006). In other cases, particularly during the emergence of new industries, innovation is driven by the market entry of entrepreneurs (Utterback, 1994). The ability of such entrepreneurs to respond to the opportunities that emerging industries offer is dependent on a range of factors,

\footnotetext{
${ }^{3} \mathrm{https}: / / \mathrm{www} . k i c k s t a r t e r . c o m / d i s c o v e r / c a t e g o r i e s / t e c h n o l o g y / 3$ d\%20printing.
}

including organisational antecedents, resources and cognitive capabilities (Eckhardt and Shane, 2003; Short et al., 2009).

The emergence of 3DP has been no different. Entrepreneurs have been the originators of new models of $3 \mathrm{D}$ printers, materials and materials processing technologies, design software, and distribution platforms (Ford and Despeisse, 2016). In addition to this entrepreneurial activity within the 3DP ecosystem, there are numerous entrepreneurs making use of the attributes of 3DP to make products and deliver services in novel ways, with a great number of these new ventures initially supported by crowdfunding on platforms such as Kickstarter. ${ }^{3}$ While opportunities in this nascent industry are primarily being realised in the traditional cradle-to-grave value chain, there is a small but growing number of entrepreneurs who are working within the $3 \mathrm{DP}$ ecosystem to create a circular economy. The focus of entrepreneurial activity in the 3DP$\mathrm{CE}$ so far has been around three categories of activities:

1) Use of 3DP for repair and remanufacturing, such as Kazzata

2) Production of 3DP filament, including the commercialisation of filament that contains recycled materials;

3) Local recycling systems for creating filament ${ }^{2}$.

Entrepreneurship scholars have yet to turn their attention to this novel combination of technology (3DP) and paradigm (CE), despite the ability to follow it live as it emerges. A starting point for investigating this phenomenon is to ask the following:

RQ4-1: How are entrepreneurs using 3DP to realise opportunities in the CE?

One of the challenges common to entrepreneurial ventures is that they possess far fewer resources (financial, human, organisational) than established companies. However, the lack of these resources provides for greater flexibility as fewer sunk investments allow the venture to experiment more rapidly with their business model and novel product-market combinations (Lubik and Garnsey, 2016). To illustrate the specific challenges facing entrepreneurs attempting to operate within the 3DP CE, a short case study is provided of Fila-Cycle, an entrepreneurial venture involved with the second categories of activities: production and commercialisation of 3DP filament.

\footnotetext{
${ }^{4}$ http://www.kazzata.com
} 


\subsubsection{Case study: Fila-Cycle}

Fila-Cycle is a market leader in the commercialisation of filament containing recycled materials. It was formed in 2014 with the intent of running business courses on technology and business impact. After buying a filament extruder later that year they realised that there was little competition in the UK for $100 \%$ recycled filaments and decided to launch the Fila-Cycle filament brand. Its first recycled filament was $\mathrm{ABS}$, which was sourced from the automotive industry. One key concern in material recycling is obtaining a consistent 'waste' input that is free from contaminants such as flame retardants. For the first rABS filament, car bumpers and dashboards were such a consistent source. The company has experimented with the production of other recycled filaments and its range now included rHIPS, rPET and rPLA. Automotive waste, commercial leftovers, white consumer goods and yogurt pots provide the waste inputs for these products.

Along with the issue of waste quality, the company faces a number of other barriers. Foremost among these is the challenge facing any entrepreneur operating in the 3DP-CE: the addressable market is contingent on the adoption of 3DP in industry and by consumers. As Fila-Cycle cofounder Scott Knowles observes "What we find is we are a niche within a niche in terms of product placement within the $3 D$ printing industry; $3 D$ printing being the first niche due to the age of the industry and the second niche being recycled plastic filaments within this industry - there are not many of us!"

As a result of the industry and technology's infancy, there is a lack of knowledge from potential customers about the technology and what can be achieved using 3DP. For FilaCycle and other companies like it selling 3DP recycled materials there is the twin marketing challenge of communicating the advantages of using 3DP and the importance of using recycled materials. As Scott comments "While the likes of recycled paper is all around, recycled plastics find it tougher to get through to the market, generally due to public perception."

Fila-Cycle also faces a scale-up challenge as their productive capacity is constrained by the availability of large extruders. Current machines can produce up to $30 \mathrm{~kg} / \mathrm{h}$ of filament. The limitation here again lies in the immaturity of the 3DP market and the wait for existing extruder manufacturers or new entrants to develop higher capacity machines.

Another challenge for entrepreneurs addressing the recycling of $3 \mathrm{DP}$ materials is the diversity of $3 \mathrm{DP}$ technologies and the different forms of materials these machines use. While filaments are used in material extrusion processes, these are relatively low-quality 3DP processes for polymers. Over time, these technologies may be superseded by resin-based processes such as stereolithography (SLA) and powder-based processes such as laser sintering. Technological and market uncertainty create a barrier to investment.

As this case study shows, there are a number of specific barriers particular to 3DP in the CE. If a CE based on 3DP is to be created then a supportive climate for entrepreneurs must be made by policymakers. In addition to answering the first research question, academics can inform policy through addressing the following:

RQ4-2: What are the barriers inhibiting entrepreneurial response using 3DP?

\subsection{Business model transformations}

Capturing value requires organisations to assess its value proposition and potential inefficiencies or innovations within their current processes. This process of capturing value is not well understood when it comes to technology applications which are not yet mature such as 3DP. Therefore a first research question to explore the business models making use of 3DP for CE is:

RQ5-1: How are organisations capturing value when using 3DP to implement CE concepts?

3DP technologies can enable the development of new value propositions and new value capture models, stimulating the access to traditional markets of new entrants (Weller et al., 2015). In particular, the use of these technologies for distributed/home fabrication holds great potential for business model innovation (Rayna and Striukova, 2016), a transformation which would involve a major shift from a manufacturer- to a consumer-centric business model (Bogers et al., 2016). This implies that firms might conceive more open business models where consumers can be more directly involved in productive and value-adding activities (Chesbrough, 2010). At the same time, these technologies could serve as foundations for the development of novel sustainable value propositions, along the eight sustainable business model archetypes proposed by Short et al. (2012). For instance, firms can identify a number of new sustainable ways of capturing value by adopting a lean-manufacturing approach while reducing inventories and excess manufacturing by managing the production of on-demand spare parts, closer to the point of consumption (Bogers et al., 2016). Opportunities also exist to increase efficiency and to create value through the use of 3DP for endof-life parts generating reuse cycles for worn out components (Van-Thao et al., 2015). Changing the relationship between manufacturers and customers presents opportunities to transform business model for CE with a service model including localised repair.

Alternatively, new business models may allow companies to deliver value to their customers in innovative ways, illustrated by FairPhone's collaboration with 3D Hubs 
network to offer customer-designed, locally-produced phone cases and accessory products, ${ }^{5}$ and in which 3D Hubs act as the value delivery channel without directly owning printers themselves. This example highlights how the combination of rapid direct manufacture and customer interaction can increase value capture through premium pricing models (Rayna et al., 2015). 3DP can facilitate combinations of CEenabling business models ${ }^{6}$ with consumer-manufacturer interactions working towards the goal of maximising energy and material efficiency. Although product suitability for these models is difficult to define, Materialise's current "golf ball" rule ${ }^{7}$ regarding the size of artefacts that are $3 \mathrm{D}$ printable at scale offers insight into the types of products that are already suitable for 3DP.

Another example of a sustainable business model is one in which manufacturing capabilities are shared across a group of firms through the development of technological platforms. For instance, the availability of machinery (3DP and other manufacturing tools) through local and online fabspaces (Mortara and Parisot, 2016) or 3D Hubs could support the delivery of functionality rather than ownership and also promote more collaborative, cost- and risk-sharing approaches to manufacturing. Networked business models aiming to capture value from waste are also emerging with companies such as Better Future Factory ${ }^{8}$ and Fila-Cycle. Through the availability of flexible and versatile technologies such as 3DP, the identification of new uses of waste material may become more common. In this case, 3DP can support the establishment of new business models which create value from waste as discussed in Section 2.2 on material supply chains and in Section 2.4 with the FilaCycle example.

Beyond the examples mentioned in this section, we need to further explore service-based business models which enable CE through the use of 3DP technologies. Thus we pose the following research question:

RQ5-2: How does the availability of 3DP for repair and remanufacturing enable service-based business models?

\subsection{Education and skills development}

Education and skills development in relation to 3DP for $\mathrm{CE}$ can be considered from several perspectives: 3DP understanding and awareness, skill development and policy making.

For firms to adopt any new technology, they need to understand it (Mortara and Ford, 2012; Arthur, 2009). This understanding allows firms to assess the relative merits of

\footnotetext{
${ }^{5}$ https://www.3dhubs.com/fairphone.

${ }^{6} \mathrm{https}: / / \mathrm{www}$.forumforthefuture.org

${ }^{7}$ http://www.inside3dp.com/inside3dp-exclusive-interviewtwikit-customize-makeunique-3d-printed-product/.
}

the technology in comparison to alternatives. One of the problems with 3DP technologies (in terms of both processes and materials) is that much of the knowledge relating to their performance is proprietary to the firms that are developing them (Baumers et al., 2015; Holweg, 2015). As such, openly accessible, neutral knowledge about these technologies is in scant supply. While we may have centuries of accessible data on processes such as casting and forming, only a tiny fraction of data for 3DP exists. This highlights the specific issue of improving understanding of the real capabilities and limitations of 3DP and making this knowledge widely available (Dickens and Minshall, 2015).

In addition to this issue of knowledge access, there is a wide range of skills-related issues that need to be considered for the adoption of any new production technology, e.g. see Eisenstein (2012) for lessons from the adoption of 2D printing over several centuries. As 3DP encompass a broad set of technologies, used in numerous different configurations and application areas, from prototyping to tool development to final product manufacture (Royal Academy of Engineering, 2013), the skills-related issues are particularly diverse (see e.g. Jaksic, 2014; Loy, 2014; Mercuri and Meredith, 2014). For example, the impact of higher levels of design freedom on the skills required of industrial designers, and the need for specific materialsrelated skills. There is also the need to consider the skills issues that specifically link 3DP to CE, which adds an additional dimension to the analysis.

3DP-related skills issues can be grouped into a number of themes (Dickens and Minshall, 2015). These include developing a curriculum for the use of 3DP technologies. Such a curriculum needs to encompass issues of design for 3DP, material selection, material specification and properties via 3DP (both virgin and recycled), material reuse, process selection, application-specific issues, testing and measurement. There is the appropriate positioning of this curriculum for use at different levels, i.e. primary, secondary, tertiary (Further Education and Higher Education), and in-work training and development. It requires consideration not just how to prepare those entering the workforce with 3DP skills, but how to ensure that those already in the workforce are able to extend their existing capabilities.

Furthermore, there is also the need to consider the ways in which 3DP technologies have the potential for people to change the way they learn about existing concepts, e.g. accelerating the design process through the use of rapid prototyping and direct experimentation with new materials or processes with 3DP (e.g. Kroll and Artzi, 2011; Jaksic, 2014).

\footnotetext{
${ }^{8}$ http://3dprintingindustry.com/2015/09/24/better-futurefactory-launches-fullyrecycledpet-abs-filament-line/.
} 
The policy implications linking 3DP, CE and skills are manifold. Analysis of technology roadmaps and public technology strategies relating to 3DP at the national level reveal the complexity of the challenges facing policymakers. Nations are taking very different approaches to the development of 3DP skills, and integrating them into other aspects of policies through diverse structures. For example, 3DP activities in Germany are being tightly bundled with Industrie 4.0 activities, emphasising the digital, connected, and system aspects of these technologies (Deutscher Bundestag, 2015). In Japan, emphasis is being placed on the ways in which 3DP technologies have the potential to 'reskill' workers in regional manufacturing clusters (METI, 2013).

3DP skills issues can also be considered in comparison to past technology and education policies. For example, the UK's Microelectronics Education Programme in the 1980s played a key role in the development of the capabilities of a generation of programmers in the UK at a time before it was entirely clear that personal computing was going to be a pervasive feature of our economy (Fothergill, 1981).

In the case of 3DP technologies, education and skills development programmes have yet to be explored. Adopting a UK perspective, we pose the following research questions:

RQ6-1: Does the UK have the correct mix of skills, workforce and industry [in 3DP] to benefit from a transition towards a circular economy?

RQ6-2: How can designers and engineers be educated about the potential applications and benefits of 3DP for the CE, and how should their skills be developed?

\section{Cross-cutting issues}

Due to the systemic nature of the phenomenon, there are overlaps between the six topics identified. The issues at these intersections are explored in this section.

In an optimistic scenario, transitioning to 3DP will lead to many more benefits for sustainability as many of 3DP's characteristics align with sustainability and circularity concepts (Ford and Despeisse, 2016). Early concepts of circularity were developed in the late 1980s and have progressively made their way into companies' strategic resource management. These concepts adopted an industry perspective on sustainability, often disregarding the role of individuals and culture in achieving more efficient use of natural resources and closed-loop circulation of materials.

The concept of industrial metabolism (Frosch and Gallopoulos, 1989; Ayres, 1989), now widely known as industrial ecology (Graedel and Allenby, 2002), emerged in response to resource scarcity and the consequent increase in material cost. A key principle of industrial ecology considers sources and sinks of natural resources, and promotes a regenerative use of resources where consumption should not exceed regeneration rate. Therefore, increasing manufacturing efficiency through process efficiency and recycling is key. Reducing material waste in process and recycling are both clear advantages with most 3DP technologies (Royal Academy of Engineering, 2013).

Industrial ecology is strongly based on a biological analogy where industrial systems are compared to natural ecosystems (Frosch and Gallopoulos, 1989; Graedel and Allenby, 2002). In such ecosystems, synergies occur naturally as individual organism maximises their own benefits by consuming the waste produced by another. Thus wastes and resources flow in a circular manner between the different ecosystem components with renewable energy powering those cycles. Industrial ecology encourages the formation of such synergies in between companies across industrial sectors, systematically seeing waste seen as an abundant, local and free resource. Researchers have explored ways in which $3 \mathrm{DP}$ could enable such synergies to be formed by looking at how locally recycled materials could find their way as inputs to 3DP processes (Kreiger et al., 2014; Garmulewicz et al., 2016). The role of 3DP in enabling recycling was examined in Sections 2.2 and 2.4.

Another key principle in circularity is taking inspiration from the natural world for the design of products and processes, as advocated by the concept of biomimicry (Benyus, 2002). The idea behind biomimicry is that nature already holds the solutions for many of our engineering problems through billions of years of development and evolution. Designs inspired by nature tend to have organic shapes which are more complex and often unachievable using traditional manufacturing techniques. 3DP enables freedom in shape and geometry in the design stage to achieve novel, free-form and enclosed structures, channels and lattices. Nature also follows an additive process that is more efficient. Design for additive manufacturing (DFAM) for components and product assemblies can mimic nature in the way they are built up (Rosen, 2007). The role of 3DP in enabling design for CE formed the focus of Sections 2.1 and 2.3.

More recent circularity concepts have shifted the perspective to include consumers and emphasise the importance of culture, education and awareness in realising circularity. This is particularly relevant as 3DP further blurs the line between producers and consumers with the rise of prosumers (Toffler, 1980) and enables more collaborative approaches to innovation (Rayna et al., 2015) as was discussed in Section 2.5.

Cradle-to-cradle concepts (Braungart and McDonough, 2002) focus on the material flows between industry (producers) and society (consumers), and the biocompatibility of materials to ensure that these flows do not cause harm to people and the environment. The cradle- 
to-cradle approach promotes non-toxicity and material purity to achieve a safer and more restorative use of resources, enable high value recycling, and retain the value embedded in materials. It also encourages upcycling where material waste can be reused for higher value application. Again, this circularity principle aligns with 3DP process as high material purity is required to reduce rejection rates. Product defects are still one of the key challenges when using 3DP technologies,

making material purity a priority requirement in 3DP processes (Petrovic et al., 2011; Baumers et al., 2016).

Finally, circular economy popularised by the Ellen MacArthur Foundation (2013) focuses on retaining the value embedded in products through product longevity and behavioural change towards products. 3DP has demonstrated high potential to enable product life extension through product redesign, repair, remanufacturing and up-gradability (Navrotsky, 2014; Matsumoto et al., 2016). Product life extension also promotes a shift from ownership to service through innovative business models to achieve a higher utilisation of products (Ford et al., 2015). Examples around business transformations driven by 3DP were presented in Sections 2.1 and 2.5.

Another positive influence of 3DP for circularity is its role in raising awareness about the impact of making things, as demonstrated by the rapidly emerging makerspace movement, and in changing perceptions about the quality of recycled materials. Democratising manufacturing by making the technology available to individual entrepreneurs and the wider public can drive the mindset shift and behavioural changes required to move towards more sustainable modes of production and consumption (Anderson, 2013; Chen et al., 2015; Kohtala and Hyysalo, 2015). The use of 3DP within networks of hobbyist designers and producers can serve as a pockets of knowledge and platforms of creativity for both 3DP and CE. On an industrial scale, the role of emerging smallerscale and "fuzzier" communities and start-ups have the potential to drive radical change in the manufacturing industry (Walsh et al., 2002). There are however a number of drawbacks such as intellectual property and knowledge management which were discussed in Sections 2.4 and 2.6, as well as quality issues discussed in Sections 2.2 and 2.4.

Although the strengths of 3DP identified in this and other papers indicate the promise for sustainability and a CE, the widespread adoption of 3DP will be disruptive and transform industrial systems in ways that cannot be accurately foreseen. While early studies indicate that 3DP could help realise a more sustainable industrial system, there is no guarantee that it will do so. The issues of knowledge and skills development to ensure that 3DP takes the sustainable path are discussed in Sections 2.1 and 2.6. There is great uncertainty regarding whether the current trajectory of 3DP adoption is creating more circular material flows or if it is leading to an alternative scenario in which increased resource consumption occurs through the combination of less efficient small-scale production, consumer demands for personalised goods, and more rapid product obsolescence. With the annual growth of the additive manufacturing industry currently in excess of $30 \%$ (Wohlers, 2016), it is essential that $\mathrm{CE}$ principles are embedded into the new manufacturing system before the adoption of 3DP reaches a critical inflection point in which negative practices become entrenched.

\section{Conclusions}

This paper has reviewed some of the broad research questions relating to 3DP and sustainability. The research agenda presented in this paper further develops these broad questions from a UK perspective by proposing six welldefined research areas to understand how 3DP can enable more sustainable modes of production and consumption, and unlock value in the CE. In addition to the two general questions "how can a more distributed manufacturing system based on 3D printing create a circular economy of closed-loop material flows?" and "what are the barriers to a circular 3D printing economy?", we propose the specific research questions listed in Table 1.

3DP is a paradigm-changing technology. It changes the way we make things, how manufacturing activities are organised, and who the stakeholders involved are. The combination of 3DP with other emerging manufacturing technologies and systems, such as Industrie 4.0, the Internet of Things, and new materials, is already changing the industrial landscape in radical ways. The characteristics of 3DP align well with sustainability and circularity principles and hold significant promise for moving society in a more sustainable direction. However our understanding of the full extent of the impact of 3DP on society is still limited. Addressing the research questions proposed in this paper will help inform practitioners and policymakers, guiding the implementation of 3DP into the industrial system so that it delivers triple bottom line benefits. 


\section{Table 1}

Research questions to explore the potential of 3DP to unlock value in the CE.

Product, service and system design

RQ1-1: What are the characteristics of 3DP processes and resulting products that enable CE principles such as re-use, modularity, upgrade, refurbishment and remanufacture?

RQ1-2: How can we enable designers to consider CE principles when using 3DP and how can this be built into the design process?

\section{Material supply chains}

RQ2-1: What are the economic, organisational and sustainability impacts of 3DP on materials supply chains?

RQ2-2: How can small-scale production, pre-processing and post-processing technologies for 3DP feedstock enable the localisation of material supply chains? RQ2-3: As a more distributed market emerges for raw materials, including consumers and SMEs, is there an accompanying increase in demand for disclosure of material data?

\section{Information structure and flows}

RQ3-1: What types of information heuristics are needed to control a circular 3DP economy?

RQ3-2: How do information heuristics enable and incentivise more efficient patterns of consumption?

\section{Entrepreneurial responses}

RQ4-1: How are entrepreneurs using 3DP to realise opportunities in the CE? RQ4-2: What are the barriers inhibiting entrepreneurial response using 3DP?

\section{Business model transformations}

RQ5-1: How are organisations capturing value when using 3DP to implement CE concepts?

RQ5-2: How does the availability of 3DP for repair and remanufacturing enable service-based business models?

Education and skills development

RQ6-1: Does the UK have the correct mix of skills, workforce and industry [in 3DP] to benefit from a transition towards a circular economy?

RQ6-2: How can designers and engineers be educated about the potential applications and benefits of 3DP for the CE, and how should their skills be developed? 
Alix, T., Vallespir, B., 2010. A framework for product-service design for manufacturing firms. IFIP Adv. Inf. Commun. Technol. 338, 644651.

Allwood, J.M., Ashby, M.F., Gutowski, T., Worrell, E., 2011. Material efficiency: a white paper. Resour. Conserv. Recycl. 55 (3), 362-381.

Anderson, C., 2013. Makers: The New Industrial Revolution. Random House Business, London.

Andrews, D., 2015. The Circular Economy, Design Thinking and Education for Sustainability. Local Economy 30(3). Sage Publications, pp. 305-315.

Aremu, A., Ashcroft, I., Wildman, R., Hague, R., Tuck, C., Brackett, D., 2013. The effects of bidirectional evolutionary structural optimization parameters on an industrial designed component for additive manufacture. Proc. Inst. Mech. Eng. B J. Eng. Manuf. (p.0954405412463857).

Arthur, B., 2009. The Nature of Technology: What it Is and how it Evolves. Allen Lane / Penguin.

Assink, M., 2006. Inhibitors of disruptive innovation capability: a conceptual model. Eur. J. Innov. Manag. 9 (2), $215-233$.

ASTM, 2012. ASTM F2792-12a: Standard Terminology for Additive Manufacturing Technologies. ASTM International, West Conshohocken, PA.

Ayres, R.U., 1989. In: Ausubel, J.H., Sladovich, H.E. (Eds.), Industrial MetabolismTechnology and Environment 23-49. National Academy Press, Washington DC.

Baechler, C., Devuono, M., Pearce, J.M., 2013. Distributed recycling of waste polymer into RepRap feedstock. Rapid Prototyp. J. 19 (2), $118-125$.

Bakker, C., Wang, F., Huisman, J., den Hollander, M., 2014. Products that go round: exploring product life extension through design. J. Clean. Prod. 69, 10-16.

Baumers, M., Tuck, C., Bourell, D.L., Sreenivasan, R., Hague, R., 2011. Sustainability of additive manufacturing: measuring the energy consumption of the laser sintering process. Proc. Inst. Mech. Eng. B J. Eng. Manuf. 225 (12), 2228-2239.

Baumers, M., Tuck, C., Wildman, R., Ashcroft, I., Rosamond, E., Hague, R., 2013. Transparency built-in. J. Ind. Ecol. 17 (3), $418-$ 431.

Baumers, M., Dickens, P., Tuck, C., Hague, R., 2015. The cost of additive manufacturing: machine productivity, economies of scale and technology-push. Tech. Forcasting Soc. Chang. 102, 193-201.

Baumers, M., Tuck, C., Wildman, R., Ashcroft, I., Hague, R., 2016. Shape complexity and process energy consumption in electron beam melting: a case of something for nothing in additive manufacturing? J. Ind. Ecol. http://dx.doi.org/10.1111/jiec.12397.

Benyus, J.M., 2002. Biomimicry: Innovation Inspired by Nature. Harper Perennial, New York.

Berman, B., 2012. 3-D printing: the new industrial revolution. Bus. Horiz. 55 (2), 155-162. Bogers, M., Hadar, R., Bilberg, A., 2016. Additive manufacturing for consumer-centric business models: implications for supply chains in consumer goods manufacturing. Tech.

Forcasting Soc. Chang. 102, 225-239.

Braungart, M., McDonough, W., 2002. Cradle to Cradle: Remaking the Way We Make Things. North Point Press, New York.

Brody, P., Pureswaran, V., 2013. The new software-defined supply chain. IBM Institute for Business Value, pp. 1-18.

Bundestag, D., 2015. Gutachten zu Forschung, innovation und technologischer Leistungsfähigkeit Deutschlands 2015. Available at http://dip21.bundestag.de/ dip21/btd/18/043/1804310.pdf (last accessed 21/04/2016).

Chandler, A.D., 1990. Scale and Scope: The Dynamics of Industrial Capitalism. Harvard University Press, Cambridge MA.

Charnley, F., Lemon, M., Evans, S., 2011. Exploring the process of whole system design. Des. Stud. 32 (2), $156-179$.

Charter, M., Gray, C., 2008. Remanufacturing and product design. Int. J. Prod. Dev. 6 (3/4), 375-392.

Chen, D., Heyer, S., Ibbotson, S., Salonitis, K., Steingrímsson, J.G., Thiede, S., 2015. Direct digital manufacturing: definition, evolution, and sustainability implications. J. Clean. Prod. 107, 615-625.

Chesbrough, H., 2010. Business model innovation: opportunities and barriers. Long Range Plan. 43 (2-3), 354-363.

Cotteleer, M.J., 2014. 3D Opportunity for Production. Deloitte Review, pp. 1-17. Cotteleer, M., Joyce, J., 2014. 3D Opportunity: Additive Manufacturing Paths to Performance, Innovation, and Growth. Deloitte Review, p. 14.

Despeisse, M., Ford, S.J., 2015. The role of additive manufacturing in improving resource efficiency and sustainability. Proceedings of the 2015 International Conference on Advances in Production Management Systems (APMS 2015), Tokyo, Japan, 5-9 September.

Dickens, P., Minshall, T., 2015. UK National Strategy for additive manufacturing, update report 2: what did the initial evidence reveal? Available at http://www. amnationalstrategy.uk (last accessed 21/04/2016)

Eckhardt, J.T., Shane, S.A., 2003. Opportunities and entrepreneurship. J. Manag. 29 (3), 333-349.

Eisenstein, E.L., 2012. The Printing Revolution in Early Modern Europe. Cambridge University Press.

Ellen Macarthur Foundation, 2013. Towards the Circular Economy - Economic and Business Rationale for an Accelerated Transition.

Ellen Macarthur Foundation, 2016. Intelligent Assets: Unlocking the Circular Economy Potential. 
Evans, S., Bergendahl, M.N., Gregory, M., Ryan, C., 2009. Towards a Sustainable Industrial System, with Recommendations for Education, Research, Industry and Policy. University of Cambridge, Institute for Manufacturing, Cambridge.

Faludi, J., Bayley, C., Bhogal, S., Iribarne, M., 2015a. Comparing environmental impacts of additive manufacturing vs traditional machining via life-cycle assessment. Rapid Prototyp. 21 (1), 14-33.

Faludi, J., Hu, Z., Alrashed, S., Braunholz, C., Kaul, S., Kassaye, L., 2015b. Does material choice drive sustainability of 3D printing? Int. J. Mech. Aerosp. Ind. Mechat. Manuf. Eng. 9 (2), 216-223.

Foran, B., Lenzen, M., Dey, C., Bilek, M., 2005. Integrating sustainable chain management with triple bottom line accounting. Ecol. Econ. 52 (2), 143-157.

Ford, S.J., Despeisse, M., 2016. Additive manufacturing and sustainability: an exploratory study of the advantages and challenges. J. Clean. Prod. 137, 1573-1587.

Ford, S.J., Despeisse, M., Viljakainen, A.M., 2015. Extending product life through additive manufacturing: the sustainability implications. Global Cleaner Production and Consumption Conference, Sitges, Barcelona, Spain, 1-4 November 2015.

Ford, S.J., Mortara, L., Minshall, T.H.W., 2016. The emergence of additive manufacturing: introduction to the special issue. Tech. Forcasting Soc. Chang. 102, 156-159. Fothergill, R., 1981. Microelectronics Education Programme: The Strategy. Department of

Education and Science, London.

Frosch, R.A., Gallopoulos, N.E., 1989. Strategies for manufacturing. Sci. Am. 261, 144-152. Garmulewicz, A., Holweg, M., Veldhuis, A.J., Yang, A., 2016. Disruptive technology as an enabler of the circular economy: what potential does 3D printing hold? Working

Paper Based on 3DP-RdM Feasibility Study, 2016

Gebler, M., Schoot Uiterkamp, A.J.M., Visser, C., 2014. A global sustainability perspective on 3D printing technologies. Energ. Policy 74 (C), 158-167.

Gibson, I., Rosen, D., Stucker, B., 2014. Additive Manufacturing Technologies: 3D Printing, Rapid Prototyping, and Direct Digital Manufacturing. 2nd ed. Springer.

Go, T.F., Wahab, D.A., Hishamuddin, H., 2015. Multiple generation life-cycles for product sustainability: the way forward. J. Clean. Prod. 95, 16-29.

Graedel, T.E., Allenby, B.R., 2002. Industrial Ecology. Prentice Hall, Englewood Cliffs, NJ, USA.

Guo, N., Leu, M.C., 2013. Additive manufacturing: technology, applications and research needs. Front. Mech. Eng. 8 (3), $215-243$.

Hague, R., Campbell, I., Dickens, P., 2003. Implications on design of rapid manufacturing. Proc. Inst. Mech. Eng. C J. Mech. Eng. Sci. 217 (1), 25-30.

Hatcher, G.D., Ijomah, W.L., Windmill, J.F.C., 2011. Design for remanufacture: a literature review and future research needs. J. Clean. Prod. 19 (17-18), 2004-2014.

Holweg, M., 2015. The limits of 3D printing. Harv. Bus. Rev. June (Available at https:// hbr.org/2015/06/the-limits-of-3d-printing [last accessed 21/04/2016]).

Huang, S.H., Liu, P., Mokasdar, A., Hou, L., 2013. Additive manufacturing and its societal impact: a literature review. Int. J. Adv. Manuf. Technol. 67 (5-8), 1191-1203.

Jaksic, N.I., 2014. Novel experiential learning practices in engineering education based on inexpensive 3D printers. Comput. Educ. J. 5 (4), 2-17.

Jiménez-González, C., Kim, S., Overcash, M.R., 2000. Methodology for developing gate-to-gate life cycle inventory information. Int. J. Life Cycle Assess. 5 (3), 153-159.

Joore, P., Brezet, H., 2015. A multilevel design model: the mutual relationship between product-service system development and societal change processes. J. Clean. Prod. 97, 92-105.

Khalili, N.R., Duecker, S., Ashton, W., Chavez, F., 2015. From cleaner production to sustainable development: the role of academia. J. Clean. Prod. 96, 30-43.

King, A.M., Burgess, S.C., Ijomah, W.L., McMahon, C.A., 2006. Reducing waste: repair, recondition, remanufacture or recycle? J. Sustain. Dev. 14 (4), 257-267.

Kohtala, C., 2015. Addressing sustainability in research on distributed production: an integrated literature review. J. Clean. Prod. $106,654-668$.

Kohtala, C., Hyysalo, S., 2015. Anticipated environmental sustainability of personal fabrication. J. Clean. Prod. 99, 333-344.

Kreiger, M.A., Mulder, M.L., Glover, A.G., Pearce, J.M., 2014. Life cycle analysis of distributed recycling of post-consumer high density polyethylene for 3-D printing filament. J. Clean. Prod. 70, 90-96.

Kroll, E., Artzi, D., 2011. Enhancing aerospace engineering students' learning with 3D printing wind-tunnel models. Rapid Prototyp. J. 17 (5), 393-402.

Lanier, J., 2014. Who Owns the Future? Simon and Schuster

Lipson, H., 2012. Frontiers in additive manufacturing: the shape of things to come. The Bridge 42 (1), 5-12.

Lovins, A.B., 1996. Negawatts: twelve transitions, eight improvements and one distraction. Energ. Policy 24 (4), 331-343.

Loy, J., 2014. eLearning and eMaking: 3D printing blurring the digital and the physical. Educ. Sci. 4, 108-121.

Lubik, S.J., Garnsey, E.W., 2016. Early business model evolution in science-based ventures: the case of advanced materials. Long Range Plan. 49 (3), 393-408.

March, J.G., 1991. Exploration and exploitation in organizational learning. Organ. Sci. 2 (1), 71-87. 
Martinez, V., Bastl, M., Kingston, J., Evans, E., 2010. Challenges in transforming manufacturing organisations into product-service providers. J. Manuf. Technol. Manag. 21 (4), 449-469.

Matsumoto, M., Yang, S., Martinsen, K., Kainuma, Y., 2016. Trends and research challenges in remanufacturing. Int. J. Precis. Eng. Manuf. Green Technol. 3 (1), 129-142. Maxwell, D., Van der Vorst, R., 2003. Developing sustainable products and services.

J. Clean. Prod. 11 (8), 883-895.

Mellor, S., Hao, L., Zhang, D., 2014. Additive manufacturing: a framework for implementation. Int. J. Prod. Econ. 149, $194-201$.

Mercuri, R., Meredith, K., 2014. An educational venture into 3D printing. 4th IEEE Integrated STEM Education Conference (ISEC 2014), 8th March 2014, Princeton, USA.

METI, 2013. FY2014 Points of Economic and Industrial Policies, August 2013. Ministry of Economy, Trade and Industry, Japan.

Mortara, L., Parisot, N., 2016. How do fab-spaces enable entrepreneurship? Case studies of 'makers' - entrepreneurs. Int. J. Manuf. Technol. Manag. Special Issue “3D Printing: the Next Industrial Revolution”.

Mortara, L., Ford, S.J., 2012. Technology Acquisitions: A Guided Approach to Technology Acquisition and Protection Decisions. Institute for Manufacturing, Cambridge. Navrotsky, V., 2014. 3D printing at Siemens power service. Available at http://www.siemens.fi/pool/cc/events/elp14/esitykset/navrotsky.pdf (last accessed 21/04/2016).

Panzar, J.C., Willig, R.D., 1981. Economies of scope. Am. Econ. Rev. 71 (2), 268-272.

Parker, D., 2010. Remanufacturing in the UK: A snapshot of the UK remanufacturing industry in 2009. The Resource Recovery Forum and the Centre for Remanufacturingand Reuse. Available at: http://www.remanufacturing.org.uk/pdf/story/1p342.pdf.

Peck, D., Kandachar, P., Tempelman, E., 2015. Critical materials from a product design per-spective. Mater. Des. 65, $147-159$.

Petrick, I.J., Simpson, T.W., 2013. 3D printing disrupts manufacturing: how economies of one create new rules of competition. Res. Technol. Manag. 56 (6), 12-16.

Petrovic, V., Gonzalez, J.V.H., Ferrando, O.J., Gordillo, J.D., Puchades, J.R.B., Grinan, L.P., 2011. Additive layered manufacturing: sectors of industrial application shown through case studies. Int. J. Prod. Res. 49 (4), 1061-1079.

Rajemi, M.F., Mativenga, P.T., Aramcharoen, A., 2010. Sustainable machining: selection of optimum turning conditions based on minimum energy considerations. J. Clean. Prod. 18 (10-11), 1059-1065.

Rayna, T., Striukova, L., 2016. From rapid prototyping to home fabrication: how 3D printing is changing business model innovation. Tech. Forcasting Soc. Chang. 102, 214-224.

Rayna, T., Striukova, L., Darlington, J., 2015. Co-creation and user innovation: the role of online 3D printing platforms. J. Eng. Technol. Manag. 37, 90-102.

Rosen, D.W., 2007. Design for additive manufacturing: a method to explore unexplored regions of the design space. Proceedings of the 18th Solid Freeform Fabrication Symposium (SFF 2007), 6-8 August 2007, Austin, TX, USA, pp. $402-415$.

Royal Academy of Engineering, 2013. Additive manufacturing: opportunities and constraints. A Summary of a Roundtable Forum Held on 23 May 2013 Hosted by the Royal Academy of Engineering, London.

Schenkel, M., Caniëls, C.J., Krikke, H., van der Laan, E., 2015. Understanding value creation in closed loop supply chains - past findings and future directions. J. Manuf. Syst. 37, 729-745.

Sempels, C., Hoffmann, J., 2013. Sustainable Innovation Strategy: Creating Value in a World of Finite Resources. Palgrave Macmillan.

Sherwood, M., Shu, L., 2000. Supporting design for remanufacture through waste-stream analysis of automotive remanufacturers. Ann. CIRP 49 (1), 87-90.

Short, J.C., Ketchen, D.J., Shook, C.L., Ireland, R.D., 2009. The concept of “opportunity" in entrepreneurship research: past accomplishments and future challenges. J. Manag. 36 (1), 40-65.

Short, S.W., Bocken, N.M.P., Rana, P., Evans, S., 2012. Business Model innovation for embedding sustainability: a practice-based approach introducing business model archetypes. Proceedings of the 10th Global Conference on Sustainable Manufacturing (GCSM 2012): Towards Implementing Sustainable Manufacturing, Istanbul, Turkey, 31 Oct - 2 Nov.

Stahel, W.R., 2013. The business angle of a circular economy - higher competitiveness, higher resource security and material efficiency. A New Dynamic: Effective Business in a Circular Economy, Ellen MacArthur Foundation, 1st ed Ellen MacArthur Foundation, London, England.

Stoneman, P., 2001. The Economics of Technological Diffusion. Wiley-Blackwell.

Sundin, E., Lindahl, M., Ijomah, W., 2009. Product design for product/service systems: design experiences from Swedish industry. J. Manuf. Technol. Manag. 20 (5), 723-753. Sundin, E., Elo, K., Lee, H.M., 2012. Design for automatic end-of-life processes. Assem. Autom. 32 (4), 389-398.

Telenko, C., Seepersad, C.C., Webber, M.E., 2008. January. A compilation of design for environment principles and guidelines. ASME 2008 International Design Engineering Technical Conferences and Computers and Information in Engineering Conference. American Society of Mechanical Engineers, pp. 289-301.

Toffler, A., 1980. The Third Wave. Bantam Books, New York.

Tuck, C.J., Hague, R.J., Ruffo, M., Ransley, M., Adams, P., 2008. Rapid manufacturing facilitated customization. Int. J. Comput. Integr. Manuf. 21 (3), 245-258.

Tukker, A., 2015. Product services for a resource-efficient and circular economy — a review. J. Clean. Prod. 97, 76-91.

Tushman, M.L., Anderson, P.C., 1986. Technological discontinuities and organizational environments. Adm. Sci. Q. 31, $439-465$.

Tushman, M.L., O'Reilly, C.A., 1996. Ambidextrous organizations: managing evolutionary and revolutionary change. Calif. Manag. Rev. 38 (4), 8-30. 
Utterback, J.M., 1994. Mastering the Dynamics of Innovation. Harvard Business School Press, Boston MA.

Van-Thao, L., Paris, H., Mandil, G., 2015. Using additive and subtractive manufacturing technologies in a new remanufacturing strategy to produce new parts from End-of-Life parts. $22^{\text {ème }}$ Congrès Français de Mécanique, Lyon, France, pp. 24-28 (August).

Vayre, B., Vignat, F., Villeneuve, F., 2012. Metallic additive manufacturing: state-of-the-art review and prospects. Mech. Ind. 13, 89-96.

Vezzoli, C., Sciama, D., 2006. Life Cycle Design: from general methods to product type specific guidelines and checklists: a method adopted to develop a set of guidelines/ checklist handbook for the eco-efficient design of NECTA vending machines. J. Clean. Prod. 14 (15-16), 1319-1325.

Vezzoli, C., Ceschin, F., Diehl, J., Kohtala, C., 2015. New design challenges to widely implement 'sustainable product-service systems'. J. Clean. Prod. 97, 1-12.

Walsh, S.T., Kirchhoff, B.A., Newbert, S., 2002. Differentiating market strategies for disruptive technologies. IEEE Trans. Eng. Manag. 49 (4), 341-351.

Weller, C., Kleer, R., Piller, F.T., 2015. Economic implications of 3D printing: market structure models in light of additive manufacturing revisited. Int. J. Prod. Econ. 164, 43-56. Whalen, K., Peck, D., 2014. In the loo- sustainable, circular product design and critical materials. Int. J. Autom. Technol. 8 (5), 664-676.

Witter, D., 2015. Plastic \& resin manufacturing in the US. IBIS World Industry Report 32521.

Wohlers, T., 2016. Wohlers report 2016: 3D printing and additive manufacturing state of the industry. Annual Worldwide Progress Report (ISBN 978-0-9913332-2-6). Wright, D., Meadows, D.H., 2008. Thinking in Systems: A Primer. Chelsea Green Publishing, White River Junction VT.

\section{Author information}

Dr Mélanie Despeisse is a Research Associate in the Centre for Technology Management, Institute for Manufacturing, University of Cambridge. Her research interests primarily focus on the relationship between industry and environmental sustainability at various scales. Since October 2015, she has been working on the RCUK-funded "Bit by Bit" project, investigating the potential role of additive manufacturing in transitioning towards a more sustainable society.

Dr Martin Baumers is an Assistant Professor in Additive Manufacturing Management with an interest in the benefits and costs of Additive Manufacturing (AM) and 3D Printing and with a background in economics. From 2010 on, Martin's work has concentrated on the development of novel approaches to production costing and build time estimation. Further areas of interest are process selection, computational build volume packing approaches and shape complexity measurement techniques. Martin also investigates the environmental sustainability of additive processes, with an emphasis on energy consumption, to assess whether AM provides a pathway to more sustainable manufacturing and also more benign products.

Phil Brown is a PhD Researcher within the circular product design team at TU Delft. His current research explores collaboration within circular value networks. He previously worked with the HSSMI Circular Value Chains team and would like to acknowledge HSSMI's support regards the time to write his contribution to this paper. He holds an MSc in Environmental Management for Business from Cranfield and is a Schmidt-MacArthur Circular Economy Fellow alumni, whereby his research explored the feasibility of recovering materials from waste electronics for 3D printing.

Dr. Fiona Charnley is a Lecturer in Sustainable Product and Service Design in Competitive Creative Design (C4D) at Cranfield University. She has experience and expertise across a range of approaches to designing for improved innovation and sustainability. Fiona has particular expertise in the process of Whole System Design; a cross-disciplinary and integrated approach to the development of more sustainable and innovative products, services and systems. Her current area of interest lies in the application of design thinking for the transition towards a circular economy.

Dr. Simon Ford joined the Centre for Technology Management as a Research Associate in January 2007. The majority of his research falls within two areas: the organisation of innovation, and the emergence and evolution of industries and technologies. His research interests also include 3D printing, entrepreneurship, serious games and sustainability.

Dr. Alysia Garmulewicz is a Professor at the Universidad de Santiago de Chile and has a Ph.D. from the Saïd Business School, University of Oxford. She researches 3D printing and the circular economy, with a focus on local materials markets for digital fabrication.

Scott Knowles is the founder of Fila-Cycle. His UK-based team are utilising automotive, commercial, and home electronic waste to create environmentally friendly plastic filaments which can be used for 3D printing. 
Dr. Tim Minshall is a Reader in Technology and Innovation Management in Cambridge University. Actively involved in new technology ventures, his early projects supported the setting up of the Cambridge Enterprise. His research interests include open innovation, university-industry collaborations, technology business investment and incubation, engineering education and digital fabrication/3D printing.

Dr. Letizia Mortara is a Senior Research Associate at the IfM's Centre for Technology Management, University of Cambridge. Her research focus is in the areas of Strategic Technology Management and Technology Enterprise. Specific research projects include technology intelligence, open innovation, and the advent of digital fabrication technologies in manufacturing and their implications for business.

Dr. Felix Reed-Tsochas is James Martin Lecturer in Complex Systems at the Said Business School, Director of the Oxford Martin Programme on Complexity. His research focuses on developing an interdisciplinary approach to understanding the dynamics and functional properties of complex networks in different contexts. He is also interested in the connection between individual and collective behaviour in social systems, and models of the emergence and structure of cooperation in biological and social systems.

Jonathan Rowley is Design Director of Digits2Widgets, a Central London based 3d printing studio. A qualified Architect, he joined Digits2Widgets at the end of 2011 in order to provide a bespoke 3d printing service utilising industrial 3d printing technology to all branches and all levels of design and manufacturing. 